\title{
TURISMO VERDE: AMIGOS, AMIGOS, NEGÓCIOS À PARTE
}

\author{
Antônio Giovanni Figliuolo Uchôa - Centro Universitário do Norte - UniNorte ${ }^{2}$ \\ Maria Leônia Alves do Vale Brasil - Centro Universitário do Norte - UniNorte ${ }^{3}$ \\ Sidnei Vieira Marinho - Universidade do Vale do Itajaí - Univali ${ }^{4}$ \\ Anete Alberton - Universidade do Vale do Itajaí - Univali ${ }^{5}$
}

Resumo: $O$ empreendedorismo possui sua força motriz no desejo de criação e inovação, permitindo agregar à economia novas oportunidades de negócios associado à diversificação de produtos e serviços. A peculiar característica de biodiversidade amazônica é palco para modelos de negócios inspiradores em associação ao ambiente natural proporcionado pela região. Neste ambiente, surge a Pousada Arara Azul, um negócio familiar, uma empresa caracterizada como alojamento ou hotel de selva, voltada para o ecoturismo. A organização atendeu inicialmente à demanda local. Contudo, as dificuldades de acesso em virtude da logística por balsas restringiram a demanda de clientes ao hotel, reduzindo a taxa de ocupação. Com a construção da ponte sobre o Rio Negro identificou-se uma possível melhora. Todavia, não foi constatado incremento nos negócios. Desta forma, é preciso questionar quais estratégias poderiam ser implementadas para incrementar a taxa de ocupação.

Palavras-chave: Estratégia; Empreendedorismo; Hotel de Selva.

\section{ECOTOURISM: BUSINESS IS BUSINESS}

Abstract: Entrepreneurship has its driving force in the desire for creation and innovation, allowing the economy to add new business opportunities associated with the diversification of products and services. The peculiar feature of Amazonian biodiversity is a stage to inspiring business models in combination with the natural environment provided by the region. In this environment, there is the Pousada Arara Azul, a family business, an enterprise characterized as a lodge or a hotel in the jungle, linked to the ecotourism. The organization initially responded to the local demand. However, the difficulties of access because the logistics by ferries, restricted the customers demand to the hotel, reducing the occupancy rate. With the construction of the bridge over the Negro River identified a possible improvement. However, it wasn't found an increase in business. Thus, it must be questioned which strategies could be implemented to increase the occupancy rate.

Keywords: Strategy; Entrepreneurship; Jungle Hotel.
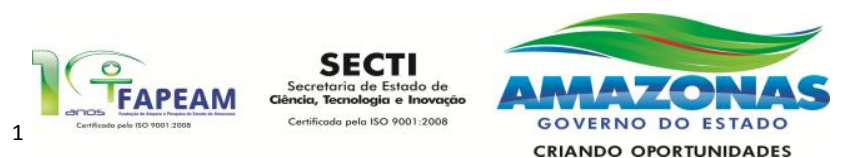

Este trabalho foi desenvolvido com o apoio do Governo do Estado do Amazonas por meio da Fundação de Amparo à Pesquisa do Estado do Amazonas.

2 E.mail: uchoag@yahoo.com.br

${ }^{3}$ Email: leonia@uninorte.com.br

${ }^{4}$ E.mail: sidnei@univali.br - Endereço: Rua João Coan, 400 - Universidade do Vale do Itajaí

- Programa de Pós-Graduação em Administração - CEP: 88160-000 - Biguaçu - SC

${ }^{5}$ E.mail: anete@univali.br

UCHÔA et al. Turismo verde: amigos, amigos, negócios à parte. Caso de ensino em empreendedorismo. Revista de Empreendedorismo e Gestão de Pequenas Empresas, v.2, n.2, p. 116-133, 2013. 


\section{Introdução}

É de verificar-se que o turismo ecológico tornou-se, nos últimos anos, uma das atividades mais difundidas no estado do Amazonas. Nada mais oportuno, tendo em vista possuir uma gigantesca floresta considerada uma das últimas e mais importantes reservas de recursos naturais. São 3,3 milhões de quilômetros quadrados somente no Brasil.

Segundo a Organização Mundial do Turismo (OMT, 2002), o planejamento, desenvolvimento e operação do turismo devem ser parte das estratégias de conservação ou de desenvolvimento sustentável para uma região. Devem ainda ser intersetoriais e integrados, envolvendo várias organizações governamentais, empresas privadas, grupos de indivíduos, permitindo, deste modo, obter benefícios.

Empreendimentos como os Hotéis de Selva, também conhecidos como lodges, ficam localizados em ambientes onde seu produto é essencialmente baseado nos atrativos naturais e culturais da região, devendo integrar-se à paisagem local, sem que haja interferência ao meio ambiente. Dados relacionados a alojamentos de selva, expressando seu processo de ampliação compreendido entre os anos de 2003 a 2011, apresentam um crescimento médio de 16\% em 2011 (Figura 1).

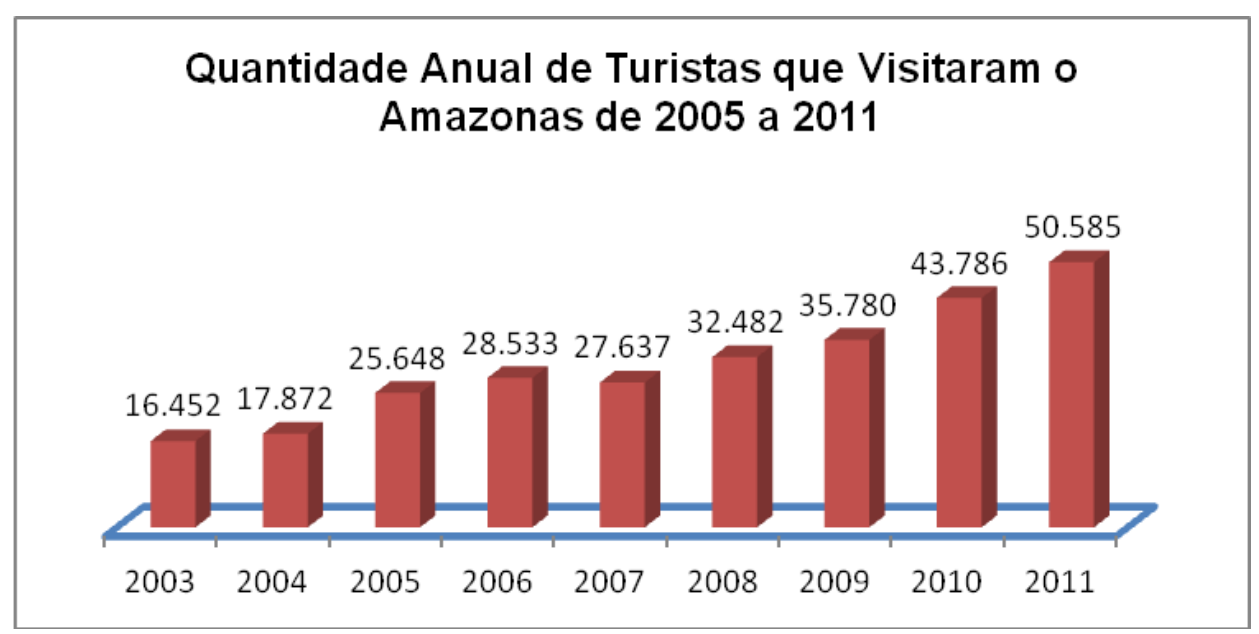

Figura 1: Turistas Visitantes Fonte: Amazonastur (2012)

UCHÔA et al. Turismo verde: amigos, amigos, negócios à parte. Caso de ensino em empreendedorismo. Revista de Empreendedorismo e Gestão de Pequenas Empresas, v.2, n.2, 2013. 
Estado do Amazonas foi contemplado para sediar a Copa do Mundo de Futebol em 2014. Esse evento por si só, vem obrigando o governo a adotar medidas de caráter estrutural que já estão promovendo transformações na cidade, seguindo o lema "desenvolver sem destruir".

Nesse contexto, os casais Gustavo e Auxiliadora, mesmo sem nenhum conhecimento no segmento de turismo e hotelaria, aproveitaram a oportunidade e transformaram a fazenda da família em um empreendimento de selva, alicerçada por uma nova infraestrutura de acesso, dada a inauguração da ponte sobre o Rio Negro. Certamente que entusiasmo e dificuldades irão se misturar na grande oportunidade de gerir um empreendimento e de se descobrir empreendedor a cada novo desafio.

\section{A Fazenda da Família}

No auge do desenvolvimento da agropecuária no Estado do Amazonas, Auxiliadora era proprietária de uma fazenda bem estruturada, com vários hectares de terra, muitas cabeças de gado, porcos, carneiros e outros animais. Possuía uma casa mãe em forma de chalé e outras duas em forma de palafitas que atendia confortavelmente a família quando precisava vir da capital para a fazenda para o seu descanso merecido. A família é sempre hospitaleira, recebendo muitos amigos, principalmente aos finais de semana.

Um belo dia, Auxiliadora se deu conta de que além da comida, também estavam incluindo na hospedagem, cama, rede, roupa de banho, enfim, um serviço completo. Em um final de semana, o casal cansado da trabalheira que tiveram e com os filhos dormindo no carro, começaram a conversar. A conversa que tiveram será transcrita a seguir.

"Auxiliadora, vamos diminuir as vindas para a fazenda, pois a cada final de semana percebo que estamos voltando mais cansados, mais estressados do que quando chegamos na sexta-feira à noite. Isso fora os gastos que estamos tendo; a Fazenda está dando prejuízo", desabafa Gustavo.

UCHÔA et al. Turismo verde: amigos, amigos, negócios à parte. Caso de ensino em empreendedorismo. Revista de Empreendedorismo e Gestão de Pequenas Empresas, v.2, n.2, 2013. 
Auxiliadora concordou, quase entrando numa soneca, dado o cansaço: "Você tem razão, estou morta de cansada, parece que um trem passou em cima de mim. Hoje não foi fácil”.

Mas Auxiliadora teve um insight rápido e logo despertou do estado letárgico. "Gustavo, apesar do cansaço, vejo que recebemos muito bem nossos amigos e eles vão embora e é só felicidade. Se tivesse como medir a felicidade deles com algumas moedas, acho que teríamos agora um belo saco de moedas. Diga-me: você não está percebendo uma boa oportunidade aí de ganharmos dinheiro?"

"Como assim?”. Indagou Gustavo.

"É, preste atenção, o seu irmão já percebeu isso e acho que ele vai querer fazer alguma coisa nesse sentido. Acho que podemos nos juntar e pensar em algo. Voltamos cansados, mas nossos amigos felizes, pois curtiram o final de semana, descansaram e aproveitaram a natureza. Você não acha que podíamos ganhar dinheiro com a nossa Fazenda?".

Gustavo não entendeu nada. E perguntou: "Como ganhar dinheiro se a gente só gasta? Eu não estou vendo nada disso. Volte a dormir, pois acho que você está sonhando".

"Preste atenção mais uma vez. Não estou dormindo, mas acho que comecei a esboçar um sonho. Vejo que temos o dom de saber receber, gostamos de dar aos nossos amigos tudo que gostaríamos que nos dessem: conforto, tranquilidade, boa comida e, claro, a amizade. Então, acho que estamos perdendo tempo e dinheiro. Se montarmos um Hotel de Selva, tenho certeza que nossos amigos vão adorar e trazer mais amigos para o nosso empreendimento. Não vamos precisar gastar com divulgação, pois a propaganda boca a boca é a alma do negócio, você não concorda?"

Na semana seguinte Paulo, irmão de Gustavo, pediu uma reunião e lançou a ideia de montar um Hotel de Selva. Paulo era empresário de outro ramo, mas estava empolgado com a possibilidade e tinha capital e conhecimento para começar. Gustavo aceitou. Nascia a ideia do Hotel de Selva.

Auxiliadora estava animada e Paulo, que gostava muito de turismo, acreditava na ideia. Gustavo deu carta branca, podiam dar continuidade. Foi para a

UCHÔA et al. Turismo verde: amigos, amigos, negócios à parte. Caso de ensino em empreendedorismo. Revista de Empreendedorismo e Gestão de Pequenas Empresas, v.2, n.2, 2013. 
rua, fez pesquisa de mercado, pegou seu capital e investiu nas adaptações das casas para dar as características de hotel. Auxiliadora ficou como Gerente Operacional e pode contribuir com suas ideias.

Alguns anos depois, Paulo se decepcionou com o ramo, negociou com o irmão e saiu, passando o controle total para o casal Gustavo e Auxiliadora.

\section{O Negócio}

Alguns meses depois, após várias conversas do casal, finalmente Gustavo concordou com o empreendimento e decidiu investir, apoiando Auxiliadora. Gustavo já possuía seu próprio negócio e decidiu somente investir na ideia e Auxiliadora tomar a frente do negócio.

Animada, Auxiliadora começou a fazer suas pesquisas para ver por onde começar, até porque queria fazer tudo de maneira correta. Então, procurou orientação junto a alguns órgãos como o SEBRAE, a Prefeitura do Município onde está inserida, os Órgãos Oficiais do Turismo, dentre outros.

A localização da Fazenda é privilegiada. Está situada em um rio com beleza natural e ímpar, com vários atrativos naturais de encher os olhos de quem por ali passa, motivo pelo qual esse rio é sede de tantos outros hotéis. Decidiram denominar o novo empreendimento de Pousada Arara Azul, com todas as características de um Hotel de Selva.

Inaugurado em 1997, com 20 UH's (Unidades Habitacionais) tinha a seguinte estrutura (Quadro 1):

\begin{tabular}{|c|c|c|c|}
\hline Chalé & Piso & Apart. & Características \\
\hline 1 & 2 & 9 & Duplo ou Triplo, camas de solteiro, casal e beliche. \\
\hline 1 & 1 & 5 & Duplo ou Triplo, ar-cond., ventilador de teto e chuveiro elétrico. \\
\hline 1 & 1 & 6 & $\begin{array}{c}\text { Duplo ou Triplo, ar-cond., ventilador de teto e chuveiro elétrico. } \\
\text { Quadro 1: Estrutura da Pousada em 1997 } \\
\text { Fonte: Desenvolvido pelos Autores (2012) }\end{array}$
\end{tabular}

UCHÔA et al. Turismo verde: amigos, amigos, negócios à parte. Caso de ensino em empreendedorismo. Revista de Empreendedorismo e Gestão de Pequenas Empresas, v.2, n.2, 2013. 
A pousada ainda oferece:

- Um restaurante/bar, uma sala de tv/vídeo, antena parabólica, um salão de jogos equipado com tv/vídeo, videokê, mesa de sinuca, de pinguepongue, mesa de baralho e dominó, além de equipamento para a prática de musculação;

- Uma piscina, quadra de areia para futebol e vôlei;

- Um auditório climatizado com capacidade para até 100 pessoas;

- Poço artesiano e luz convencional. Para emergência tem gerador próprio.

\section{A Expansão}

O negócio começou a dar certo. Em 2000, uma professora de Turismo de uma faculdade particular teve acesso às fotos de um grupo de Melhor Idade do Sesc que passou um fim de semana no empreendimento. A professora ficou interessada em conhecer a pousada com os alunos. Fez o primeiro contato com Auxiliadora que vibrou de alegria com a chance de poder abrir sua pousada como laboratório acadêmico para os alunos.

A parceria foi tão desejada, que Auxiliadora foi com sua gerente de vendas apresentar o seu produto para duas turmas. Foi amor à primeira vista. Fecharam um pacote para estudantes para um pernoite, vivido com muita intensidade pelos acadêmicos. Essa foi a primeira de muitas visitas técnicas ao empreendimento.

Uma grande surpresa aconteceu quando entre os primeiros alunos visitantes estava o gerente de recursos humanos de uma empresa de grande porte. Esse aluno/gerente estava à procura de um local para desenvolver uma programação de treinamentos para os funcionários de uma empresa. Ele fechou uma parceria responsável por boa parte do investimento em novas construções para a expansão da Pousada Arara Azul.

A Arara Azul conta atualmente com 35 UH'S (Unidades Habitacionais) e 105 leitos. Sendo estes distribuídos da seguinte forma (Quadro 2):

UCHÔA et al. Turismo verde: amigos, amigos, negócios à parte. Caso de ensino em empreendedorismo. Revista de Empreendedorismo e Gestão de Pequenas Empresas, v.2, n.2, 2013. 


\begin{tabular}{|c|c|c|}
\hline Suítes & Tipo & Características \\
\hline 21 & Triplo & 03 camas de solteiro e/ou 01 cama de casal e 01 de solteiro \\
\hline 12 & Quádruplos & 01 cama de casal e 01 beliche \\
\hline 01 & Óctuplo & 02 camas de casal, 02 de solteiro e 01 beliche \\
\hline 01 & Dupla & 01 cama de casal \\
\hline
\end{tabular}

Quadro 2: Estrutura da Pousada (Atual)

Fonte: Desenvolvido pelos Autores (2012)

O ano de 2004 foi um ano bom, pois estava bem perante sua clientela. Sem dinheiro para investir em propaganda, colocava seu material publicitário nos hotéis e junto ao órgão oficial de turismo para a realização de eventos promocionais do Estado, tanto nacionais como internacionais. Outro espaço de divulgação era o seu portal na Internet. O resto foi no boca a boca.

\section{Demanda}

A Pousada Arara Azul é um meio de hospedagem do tipo ambiental ou ecológico, classificado pela EMBRATUR como um alojamento de selva. Gustavo e Auxiliadora trabalharam inicialmente o público local, principalmente para aqueles a quem os proprietários denominam de "residentes", em sua maioria, moradores da cidade de Manaus. Vale destacar os contratos com pessoas jurídicas para a realização de eventos e treinamentos. Com o processo de divulgação, o mercado internacional se fez presente. Operadoras apresentaram um público com origem nos Estados Unidos, Inglaterra, Canadá, Alemanha, entre outros, mantendo a taxa de ocupação por um longo tempo.

A pousada oferece produtos e serviços que são a essência da hotelaria, como o fornecimento de alojamento, alimentação e entretenimento, e alguns complementares como um espaço destinado a atividades esportivas, por exemplo, a musculação. Dentre os produtos oferecidos pelo empreendimento, os de maior destaque são as programações náuticas, caminhadas orientadas, visitas às áreas do entorno da pousada e às comunidades, incluindo as indígenas - dependendo do 
pacote - com preços competitivos e refletindo a realidade dos mercados concorrentes.

\section{Concorrência}

A pousada, por estar localizada em uma área (cidade de Iranduba, inclusa na categoria de polo ecoturístico) onde se encontra concentrada a maioria dos hotéis desse segmento e também por possuir características muito similares, no início de suas atividades não considerava os empreendimentos como concorrentes. Isto porque, apesar das semelhanças nos seus atrativos, o porte era menor atraindo grupos menores diferentemente dos demais, que possuíam estrutura maior para atender grupos maiores.

Hoje, o quadro é um pouco diferente, visto que existem mais empreendimentos, inclusive devido ao porte do estabelecimento. Possuem agora estratégias de marketing mais ousadas e conseguem impactar o negócio, valendo citar: Ariaú Tower, Acajatuba, Tiwa Amazon Eco Resort, Amazon Fish, Pousada Ecológica, Hotel de Selva Lago Salvador, Tariri Amazon Lodge e outros. (RIBEIRO et al., 2012).

\section{Produtos}

Além dos serviços de hospedagem, a pousada oferece também pacotes organizados que variam entre um a três dias, podendo se prolongar conforme o interesse do turista. Tais pacotes podem incluir as seguintes atividades: traslado, alimentação, hospedagem, caminhada na selva, pescaria, passeios pelos igapós para reconhecimento da fauna e flora, focagem de jacaré, visita à casa do caboclo, apreciação do nascer do sol, visita à vitória-régia. A infraestrutura para a realização dessas atividades inclui canoas motorizadas, barqueiros profissionais e guias com conhecimento profundo da região.

UCHÔA et al. Turismo verde: amigos, amigos, negócios à parte. Caso de ensino em empreendedorismo. Revista de Empreendedorismo e Gestão de Pequenas Empresas, 
De acordo com o Diagnóstico e Análise de Polos de Ecoturismo do Estado do Amazonas do Ministério do Meio Ambiente, todos os empreendimentos de selva possuem as mesmas atividades em seu portfólio de produto.

\section{Equipe de Funcionários}

A estrutura organizacional é de uma empresa familiar sem organograma formal, assim todas as decisões são tomadas pelos proprietários: Gustavo (SócioProprietário) e Auxiliadora (Gerente Operacional). Atualmente possui um quadro funcional composto por quinze trabalhadores, todos com formação básica. Alguns funcionários do escritório cursam nível superior. A mão de obra da pousada é da própria comunidade com baixa rotatividade, fato incomum no setor.

Com um quadro de oito funcionários que desenvolvem suas funções há mais de oito anos, três estão desde o início das atividades e ainda há aqueles que saem e depois retornam. Merece destaque o cozinheiro Wallace, famoso por seus pratos da culinária amazônica e a figura de Samuel, guia conhecedor da região, habilidoso na arte da "peconha" (corda que é amarrada nas pernas para ajudar a subir, utilizada pelo caboclo da região).

\section{Os Espinhos no Caminho}

A pousada, apesar de possuir localização próxima à cidade, possuía um fator que impedia o seu crescimento ou o desenvolvimento de suas atividades: a travessia do Rio Negro via sistema de balsas (casos de três a cinco horas de atraso). A cada dia, o serviço se tornava mais precário, inibindo a clientela. Quem ia para descansar, ao retornar enfrentava grande estresse, em função das filas "quilométricas" para a travessia. Os grupos de executivos que iam participar de reuniões de negócio perdiam muito tempo na fila da balsa e a pousada começou a perder sua clientela.

Em função das distâncias e o tempo de acesso, empreendimentos deste tipo mantêm funcionários trabalhando por 15 dias ininterruptos. Cargos de gestão 
caracterizam-se pela dificuldade em contratação, de conseguir a mão obra especializada e de sua permanência no local. Dificuldades no desenvolvimento dos seus processos, funcionários desmotivados, a falta de manutenção, comprometem a organização como um todo em função da ausência do gestor.

Neste momento, vale lembrar os desafios apresentados no início deste artigo: A Copa do Mundo e a ponte que se pensava ser o gargalo. A ponte foi concretizada (acesso agora em 40 minutos) e os proprietários não querem se desfazer da pousada, já mais valorizada e localizada em um dos municípios que fazem parte da Região Metropolitana de Manaus. Vários investimentos estão sendo feitos com nítida valorização.

Sem grandes conhecimentos da área e recursos para investir, dentre outros problemas, a pousada passa por um momento de incertezas, dentre eles: a gestão do negócio e a possibilidade de expansão ou o encerramento das operações. Uma leitura deficiente do negócio somente alimentada por uma iniciativa empreendedora, mas desprovida de formação estratégia de manutenção e expansão, superam a boa vontade e não enriquecem uma estrutura racional sobre o empreendimento e as possibilidades futuras. Uma análise sobre a situação da empresa e seus produtos é necessária, antes de objetivar qualquer decisão e a construção de estratégias.

\section{Alguns Caminhos Encontrados para o Futuro}

O desespero bateu quando Auxiliadora, em 2010, observou seu empreendimento apresentar baixa taxa de ocupação sem nenhuma atratividade, mas a custos fixos permanentes. O que fazer se não tem capital para investir? Pensou.

"Vou procurar a faculdade que sempre me apoiou". Lembrou Auxiliadora. "Vou ligar para a professora que sempre acreditou no nosso projeto. Preciso de socorro e é urgente". Disse Auxiliadora.

Após ouvir Auxiliadora, a professora encaminhou a situação à Empresa Junior. Professores e alunos consultores ouviram atentamente a proprietária e, com base em conhecimentos teóricos e soluções práticas, decidiu-se inicialmente fazer

UCHÔA et al. Turismo verde: amigos, amigos, negócios à parte. Caso de ensino em empreendedorismo. Revista de Empreendedorismo e Gestão de Pequenas Empresas, v.2, n.2, 2013. 
um diagnóstico. A partir dessa conversa, algumas orientações foram dadas e partiuse para a elaboração do Planejamento Estratégico para a pousada. Com o conhecimento da proprietária, ações que demandariam baixo recurso foram elaboradas.

Com o interesse em atrair clientela, o marketing recebeu foco principal. Com a inauguração da ponte sobre o Rio Negro em outubro de 2011, não haveria mais o obstáculo da balsa.

Assim, a equipe de Consultores do Curso de Turismo desenvolveu uma feira de produtos turísticos, onde o foco era a Pousada Arara Azul. Como resultado o grupo apresentou seis novos pacotes para serem comercializados imediatamente e retomar seu posicionamento competitivo.

No dia da apresentação, Auxiliadora ficou emocionada com as possibilidades. Conjuntamente com a área comercial do empreendimento e os Consultores da área de Marketing e Administração, o processo de divulgação e venda deu início a uma nova etapa.

\section{NOTAS DE ENSINO}

\section{Situação-problema}

Auxiliadora tem em mãos uma grande decisão a tomar: será que a forma com que a pousada vem sendo gerenciada atende as necessidades do meio de hospedagem para ser competitiva? Será que o marketing utilizado com a diversificação dos seus produtos está sendo utilizado de forma estratégica? Essas são as questões centrais do caso e para tanto, é recomendado uma discussão com origem em estudos no formato interdisciplinar com viés empreendedor.

2 Objetivos educacionais do caso

Espera-se o aprofundamento das questões estratégicas e tomadas de decisão relacionadas a produtos e serviços atrativos para com a segmentação de

UCHÔA et al. Turismo verde: amigos, amigos, negócios à parte. Caso de ensino em empreendedorismo. Revista de Empreendedorismo e Gestão de Pequenas Empresas, v.2, n.2, 2013. 
mercado voltado para o ecoturismo ou turismo de selva. A intenção é configurar um ambiente de negócios empreendedor para inserção do aluno e posicioná-lo estrategicamente sobre o mercado, determinar produtos e serviços em associação ao incremento da taxa de ocupação do hotel.

Espera-se afinal que o aluno explore conhecimentos sobre:

- Planejamento e o processo utilizado na análise da situação via SWOT;

- Determinar um plano sobre produtos e serviços em hotelaria;

- Determinar estratégias de gestão.

\section{Utilização e recomendação}

O caso foi elaborado para ser utilizado em disciplinas que abordem o tema de Empreendedorismo, Gestão Estratégica, Administração Mercadológica, Marketing Turístico, podendo ser trabalhado na graduação, como também em pósgraduação.

4 Fontes de obtenção de informação do caso

Os dados primários foram obtidos em entrevista pessoal com Auxiliadora e Gustavo durante vários estudos feitos no seu empreendimento desde o ano de 2003 até os dias atuais, onde são desenvolvidas Visitas Técnicas por alunos de Administração e Turismo, com o objetivo de desenvolverem práticas da disciplina de Empreendedorismo. Os dados primários foram complementados por dados secundários, obtidos por meio de consulta à página da Internet da organização e sites oficiais de turismo Federal e Estadual.

5 Relevância da temática

O Ecoturismo vem despertando interesse sobre uma segmentação de mercado que busca o contato com a natureza e o conhecimento por regiões distintas dos ambientes urbanos das cidades grandes. Contudo, a necessidade de 
conhecimentos e estratégias para lidar com este mercado e suas necessidades se faz presente e oportuno.

6 Questões para discussão

1. Quais os comportamentos empreendedores podem ser identificados nos perfis dos atores deste caso?

2. O que Auxiliadora deve fazer para compreender o cenário atual e as perspectivas futuras da pousada?

3. Como construir a estratégia de marketing a ser adotada?

7 Análise do caso

As questões relacionadas ao caso podem ter seu princípio de análise sobre a compreensão do negócio com visão estratégica. Espera-se que o aluno, mediante o descrito, possua a capacidade de interpretar o ambiente de negócio, identificando as qualidades potenciais da empresa, o mercado onde está inserida e o novo cenário apresentado. Tal diagnóstico leva à necessidade de planejamento de objetivos potenciais, os quais alicerçados por ferramentas de mercadologia permitem criar projetos originalmente concebidos com baixo orçamento.

A ideia é potencializar os recursos disponíveis e tornar a empresa evidente ao mercado, assegurando uma taxa de ocupação ao negócio. O caso apresenta um histórico dos fatos ocorridos no passado e a evidente perda do controle sobre sua rentabilidade, potencializando uma discussão sobre as decisões a serem tomadas pelo empreendedor. Para melhor visualização, será indicado nas repostas a localização no texto (página/parágrafo).

7.1 Quais os comportamentos empreendedores podem ser identificados nos perfis dos atores deste caso?

UCHÔA et al. Turismo verde: amigos, amigos, negócios à parte. Caso de ensino em empreendedorismo. Revista de Empreendedorismo e Gestão de Pequenas Empresas, v.2, n.2, 2013. 
Avaliar um indivíduo e determinar seu sucesso como empreendedor ainda não é uma alternativa factível. Contudo, características comuns podem ser elencadas na identificação como indivíduos em respostas ao seu meio, "protótipo do ser social", reflexo da cultura, necessidade e hábitos regionais. Kotter (1997) adiciona a necessidade de visão de futuro e as estratégias para alcançá-las como características de uma liderança empreendedora. Modelos de negócio préexistentes em família são determinantes do comportamento, formando um blend com características como tenacidade e criatividade (ver quadro 3 adaptado de Filion (1999) a partir de uma releitura de vários autores).

\begin{tabular}{|l|l|l|}
\hline \multicolumn{3}{|c|}{ Características Empreendedoras } \\
\hline Inovação & Otimismo & Tendência a confiar nas pessoas \\
\hline Criatividade & Iniciativa & Habilidade de conduzir situações \\
\hline Originalidade & Autoconsciência & Tolerância à ambiguidade e à incerteza \\
\hline Independência & Autoconfiança & Riscos moderados \\
\hline Liderança & Necessidade de realização & Envolvimento a longo prazo \\
\hline Energia & $\begin{array}{l}\text { Capacidade de } \\
\text { aprendizagem }\end{array}$ & Habilidade na utilização de recursos \\
\hline Tenacidade & Flexibilidade & Orientação para resultado \\
\hline Agressividade & Sensibilidade a outros & Dinheiro como medida de desempenho \\
\hline \multicolumn{2}{|c|}{ Quadro 3: Características Empreendedoras (Comportamentalista) } \\
\hline
\end{tabular}

O autor acrescenta como fatores determinantes e de influência: a formação do empreendedor, as características observadas em indivíduos ao tornarem-se empreendedores e sua permanência no negócio associada à capacidade de aprendizagem de forma evolutiva na liderança de seus projetos, inovando e criando soluções. Corroborando com Kouzes e Posner (2007), identifica-se Auxiliadora como empreendedora por "fazer suas pesquisas para ver por onde começar, até porque quer fazer tudo certo, então procurou orientação junto aos órgãos como o SEBRAE, Prefeitura do Município onde está inserida, os Órgãos Oficiais do Turismo, entre outros".

O texto apresenta Paulo, irmão de Gustavo, e "empresário de outro ramo, mas empolgado com a possibilidade e tinha capital para começar". Segundo Filion

UCHÔA et al. Turismo verde: amigos, amigos, negócios à parte. Caso de ensino em empreendedorismo. Revista de Empreendedorismo e Gestão de Pequenas Empresas, v.2, n.2, 2013. 
(1999), empreendedores são "pessoas que aproveitavam as oportunidades com a perspectiva de obterem lucro, assumindo os riscos inerentes".

Já Gustavo: "possuía seu próprio negócio e que não vai largar para ficar com esse. A ideia é investir e Auxiliadora tomar a frente do negócio." Filion (1999) destaca "que as pessoas apresentam mais chances de tornarem-se empreendedores se houver um modelo em família".

7.2 O que auxiliadora deve fazer para compreender o cenário atual e as perspectivas futuras da pousada?

Em função da gestão deficiente e a falta de experiência, a proprietária procurou ajuda junto à uma universidade com uma Empresa Junior (9/4) para uma análise do negócio.

Segundo Westwood (2008), compreende-se SWOT como avaliação das capacidades internas versus o ambiente externo:

- Ambiente Interno: Pontos Fortes (Strengths) e Pontos Fracos (Weaknesses). Referem-se às capacidades internas da organização e seus produtos;

- Ambiente Externo: Oportunidades (Opportunities) e Ameaças (Threats). Entendem-se como fatores sobre os quais não se exerce controle contexto social, político, econômico.

Mintzberg (2000) argumenta que "Estratégia é um padrão, isto é, consistência em comportamento ao longo do tempo". As empresas planejam seu futuro e desenvolvem um processo de aprendizagem com base na experiência. 
Análise SWOT

\begin{tabular}{|c|c|}
\hline \multicolumn{2}{|c|}{ Análise SWOT } \\
\hline \multicolumn{2}{|c|}{ Ambiente Interno } \\
\hline Pontos Fortes & Pontos Fracos \\
\hline $\begin{array}{l}\text { Localização } \\
\text { Estrutura do Hotel } \\
\text { Mão de Obra local - operacional } \\
\text { Cozinha regional } \\
\text { Guia local }\end{array}$ & $\begin{array}{l}\text { Pacotes turísticos } \\
\text { Conhecimento sobre o ramo } \\
\text { Falta de um Gestor fixo } \\
\text { Normatização de processos } \\
\text { Motivação da equipe } \\
\text { Manutenção deficiente }\end{array}$ \\
\hline \multicolumn{2}{|c|}{ Ambiente Externo } \\
\hline Oportunidades & Ameaça \\
\hline $\begin{array}{l}\text { Turistas Visitando o Amazonas } \\
\text { Eventos de grande Repercussão } \\
\text { Ponte sobre o Rio Negro }\end{array}$ & Novos Entrantes \\
\hline
\end{tabular}

Quadro 4: Análise Interna e Externa (SWOT)

Fonte: Desenvolvido pelos Autores (2012)

A Escola do design - SWOT - é de grande influência e expressão nos meios acadêmicos e empresarias (Quadro 4). Contudo, cada indivíduo possui uma perspectiva diferenciada ou interpretação sobre estratégia, por vezes tomando como característica ou particularidade determinado foco. Este enfoque particular, interessante e oportuno, incrementa a concepção processual da estratégia em superação à falta de uma cultura de análise de aperfeiçoamento contínuo (COSTA, 2007).

A análise demonstra pontos favoráveis ao negócio descritos no decorrer do texto como: a localização, a estrutura do hotel expressa por atrativos naturais e infraestrutura de alojamento adequada. Ainda, a culinária regional operacionalizada com sucesso pelo cozinheiro Wallace e a atração à parte do guia Samuel, colaboradores de um quadro funcional de baixa rotatividade.

Os pontos fracos retratam deficiências que poderiam ser associadas à pouca experiência e conhecimento da proprietária do ramo. Os pacotes turísticos com baixa diferenciação e a ausência de uma liderança na gestão operacional fixa o local mais próximo dos funcionários, e são traduzidos na ausência de processos ou rotinas normatizadas, gerando desmotivação e uma manutenção do negócio deficiente ou imediatista.

UCHÔA et al. Turismo verde: amigos, amigos, negócios à parte. Caso de ensino em empreendedorismo. Revista de Empreendedorismo e Gestão de Pequenas Empresas, v.2, n.2, 2013. 
A análise do ambiente externo apresenta um quadro oportuno com um crescente aumento do número de visitantes à região. Esse incremento é precedido por eventos importantes, favorecendo investimentos, como o apresentado pela construção da ponte sobre o Rio Negro.

O cenário apresenta um conjunto de fatores como localização, infraestrutura e demanda cresceste, estimulando a entrada de novos players. O texto retrata os novos entrantes com estratégias de marketing diferenciadas, ponto este a ser explorado.

7.3 Como construir a estratégia de marketing a ser adotada?

Westwood (2008) define três tipos de estratégias permitindo a análise para a tomada de decisão:

a) Estratégias defensivas - elaboradas para a manutenção dos clientes, evitando sua perda: melhorar a imagem da empresa; qualidade/confiabilidade do produto/serviço; confiabilidade das promessas de entrega; desempenho/durabilidade de um produto;

b) Estratégias de desenvolvimento - elaboradas para oferecer aos clientes variedades maiores de produtos ou serviços: aumentar a variedade de serviços oferecidos; desenvolver um novo produto; aumento da variedade de características/opções extras oferecidas;

c) Estratégias de ataque - são elaboradas com intenção de expansão ou novos clientes: mudança na política de preço; expansão dos limites geográficos; utilizar novos canais de venda.

A Estratégia de Marketing deve representar possibilidades futuras associadas aos resultados da empresa, tendo em específico o conhecimento sobre segmentos, produtos e programas, capazes de determinar participação de mercado e vendas em associação à satisfação do cliente.

Middleton (2002) argumenta que "essencialmente, qualquer estratégia engloba uma declaração de metas e objetivos, uma estrutura de recursos necessários e programas de atividades destinados a atingir as metas". 
O texto informa um crescimento de $16 \%$ de visitantes ao Amazonas devido a Copa do Mundo e a melhoria da logística com a entrega da ponte sobre o Rio Negro. As características do empreendimento definem um potencial para uma Estratégia de Desenvolvimento, potencializando a criação de novos produtos ou serviços. No tópico Expansão, há o incremento da estrutura (75\% em UH's), mas observa-se falta de diferenciação e gestão. Este último complicou-se devido ao afastamento de Paulo e Gustavo, os mais experientes em negócios.

\section{REFERÊNCIAS}

AMAZONASTUR, Empresa Estadual de Turismo do Amazonas. Síntese dos Indicadores de Turismo do Estado do Amazonas. (2003-2011). Disponível em: <http/www.visitaamazonas.am.gov.br>. Acesso em: 15 jul. 2012.

COSTA, E. A. Gestão Estratégica: da empresa que temos para a empresa que queremos. 2. ed. São Paulo: Saraiva, 2007.

FILION, L. J. Empreendedorismo: empreendedores e proprietários-gerentes de pequenos negócios. Revista de Administração, São Paulo, v. 34, n. 2, p. 05-28, abril/junho, 1999.

KOTTER, J. P. Liderando mudança. Tradução de Leading Change. Rio de Janeiro: Campus, 1997.

KOUZES, J. M.; POSNER, B. Z. The leadership challenge. 4. ed. San Francisco, CA: Jossey-Bass, 2007.

MIDDLETON, V. T. C. Marketing de Turismo: teoria e prática. 2ª reimpressão. Rio de Janeiro: Elsevier, 2002.

MINTZBERG, H.; AHLSTRAND, B.; LAMPEL, J. Safári de Estratégia: um roteiro pela selva do planejamento estratégico. Porto Alegre: Bookman, 2000.

OMT. Contribuciones de la organización mundial del turismo a la cumbre mundial sobre el desarrollo sostenible. Johannesburgo, 2002.

RIBEIRO, E. M. et al. Comunidades à margem da sustentabilidade: um olhar sobre o Polo Ecoturístico de Iranduba (AM). Revista Brasileira de Ecoturismo, São Paulo, v. 5, n. 1, p. 11-26, jan/abr, 2012.

WESTWOOD, J. O Plano de Marketing. 3. ed. São Paulo: M. Books do Brasil Editora, 2008.

Caso de ensino recebido em 22/07/2013. Aprovado em 03/08/2013.

UCHÔA et al. Turismo verde: amigos, amigos, negócios à parte. Caso de ensino em empreendedorismo. Revista de Empreendedorismo e Gestão de Pequenas Empresas, v.2, n.2, 2013. 